\title{
Efficacy and Tolerability of Split-Dose PEG Compared with Split-Dose Aqueous Sodium Phosphate for Outpatient Colonoscopy: A Randomized, Controlled Trial
}

\author{
Eun Hee Seo • Tae Oh Kim • Tae Gyoon Kim • Hee Rin Joo • \\ Min Jae Park · Jongha Park $\cdot$ Seung Ha Park $\cdot$ Sung Yeon Yang • \\ Young Soo Moon
}

Received: 22 March 2011/Accepted: 28 May 2011/Published online: 9 June 2011

(C) The Author(s) 2011. This article is published with open access at Springerlink.com

\begin{abstract}
Background and Aims Adequate bowel cleansing is essential for a high-quality, effective, and safe colonoscopy. The aims of this study were to compare the efficacy and tolerability of split-dose polyethylene glycol with aqueous sodium phosphate for outpatients who underwent scheduled colonoscopy.

Methods In this prospective trial, 207 outpatients (aged between 18 and 65 years, with normal renal function, at low risk for renal damage) were randomized to receive split-dose preparation of PEG $(2 \mathrm{~L} / 2 \mathrm{~L})(N=103)$ or NaP (45 mL/45 mL, $12 \mathrm{~h}$ apart) $(N=104)$ without strict diet restriction the day before colonoscopy. The bowel cleansing efficacy of preparations was rated according to the Ottawa scale and the patient tolerability was assessed using a patient questionnaire.

Results There was no significant difference between the two groups for the mean total score using the Ottawa bowel preparation scale $(P=0.181)$. Significantly greater residual colonic fluid was observed in the split-dose PEG group $(1.24 \pm 0.49)$ than in the NaP group $(1.04 \pm 0.53)(P=$ 0.007). Patient compliance, preference, and acceptance of a two preparation regimen were similar with no significant differences $(P=0.095, P=0.280$ and $P=0.408$, respectively). The overall incidence of adverse events was not significantly different between the two groups; however, the split-dose PEG group tended to have fewer
\end{abstract}

E. H. Seo - T. O. Kim ( $₫)$ - T. G. Kim · H. R. Joo •

M. J. Park - J. Park - S. H. Park - S. Y. Yang - Y. S. Moon

Department of Internal Medicine, Haeundae Paik Hospital,

Inje University School of Medicine, 1435 Jwa-dong,

Haeundae-gu, Busan 612-030, Republic of Korea

e-mail: kto0440@yahoo.co.kr adverse events (52/103 [50.5\%], 66/104 [63.5\%], $P=$ $0.059)$ and had significantly less nausea and vomiting $(P=0.036)$.

Conclusions Split-dose PEG, compared with split-dose $\mathrm{NaP}$, is associated with more residual colonic fluid, but produces equivalent colon cleansing efficacy and results in less nausea and vomiting, which might improve patient tolerability (clinical trial registration number NCT01229800).

Keywords Colonoscopy - Bowel preparation . Polyethylene glycols . Sodium phosphate

\section{Introduction}

Adequate bowel cleansing is essential for a successful examination of the colon mucosa during a colonoscopy. Inadequate bowel preparation leads to longer duration of colonoscopy, and decreased rates of identifying lesions $[1,2]$. The ideal bowel preparation would completely clear the colon without any solid or liquid material, with no change of the gross or microscopic features of the colon mucosa. In addition, the ideal regimen should be easy to ingest, cause no patient discomfort, and have no adverse effects, including fluid or electrolyte imbalance [3]. However, there is no available ideal regimen to meet all of these criteria. Polyethylene glycol (PEG) and oral sodium phosphate (NaP) are the two commercially available regimens used most widely for colonoscopy bowel preparation. PEG is a non-absorbable solution that should pass through the bowel without net absorption or secretion and it generally produces no significant fluid or electrolyte disturbance, which is a great advantage over NaP. However, patients are required to ingest a large volume of fluid, leading to decreased compliance. Recently, several studies 
have suggested that a split-dose PEG is more effective for bowel cleansing than conventional one-dose PEG and enhances patients' compliance and tolerability by reducing fluid volume to ingest once [4-7]. In addition, patients ingesting split-dose PEG are not required to have only clear liquids, and only slight restriction of diet is required on the day before colonoscopy. Thus, split-dose PEG is now commonly used for bowel preparation, especially for outpatients.

Several randomized trials comparing conventional onedose PEG and oral NaP preparations have suggested that $\mathrm{NaP}$ is safe, better tolerated, and equally or more effective for bowel cleansing than one-dose PEG solution [8-13]. Recently, several reports of acute phosphate nephropathy associated with sodium phosphate bowel preparation have been published [14-19]. However, the majority of published cases of adverse events related to sodium phosphate bowel preparations were associated with definite or probable predisposing factors including improper dosing, inadequate hydration, and medical contraindications to the use of sodium phosphates. Most of the published reports provide no information on hydration. And, the populations evaluated in previous studies had considerable heterogeneity with a variety of indications for colonoscopy and differing health status. The United States FDA issued a safety alert in December 2008, stating that oral NaP for colon cleansing before colonoscopy should only be available by prescription. But, $\mathrm{NaP}$ solution still remains available for bowel preparation for colonoscopy because of its advantage such as good efficacy, low cost and high level of tolerability in Korea, Canada and other countries [2022]. Additionally, several studies recently demonstrated that renal failure did not occur after the use of $\mathrm{NaP}$ for bowel preparation in patients with recently documented normal renal function who consume enough water after each dose [20, 23].

To the best of our knowledge, there has been no large randomized controlled trial to compare split-dose PEG with split-dose NaP for bowel preparation for outpatient colonoscopy. Thus, we planned to compare split-dose PEG with split-dose NaP preparation for colonoscopy in outpatients with normal renal function, based on the hypothesis that spilt-dose PEG would have better efficacy for bowel preparation and equal or better tolerability and safety compared with split-dose NaP.

\section{Materials and Methods}

This was a prospective, randomized, investigator-blinded study comparing split-dose PEG with split-doses NaP for patients undergoing colonoscopy. All patients provided written informed consent. This study was approved by the institutional review board. The protocol was registered on ClinicalTrials.gov (NCT01229800).

\section{Subjects}

Safety issues of oral sodium phosphate $(\mathrm{NaP})$ solution have emerged, which have led to questions concerning the risk/ benefit of this agent. So, we were careful about four key components for safe colon preparation prior to colonoscopy for outpatients: proper separated dosing and hydration, awareness of contraindications and precautions, adequate patient instruction, and patient compliance. Inpatient colonoscopy recipients are more likely to have an underlying disease and more likely to develop kidney injury compared with asymptomatic healthy persons. Therefore, we enrolled all healthy outpatients. All consecutive outpatients or patients visiting the health screening center between the ages of 18 and 65 years with recently documented normal renal function who were scheduled to undergo colonoscopy were eligible. This study was conducted at a single university hospital, Haeundae Paik Hospital in Busan, Korea, between August and October 2010. According to the U.S. Food and Drug Administration (FDA) recommendations to avoid renal damage with $\mathrm{NaP}$, patients with the following conditions were excluded: age under 18 years or above 65 years; previous colorectal surgery; bowel obstruction, and other structural intestinal disorders; gut dysmotility; presence of renal failure, congestive heart failure, or liver failure; active colitis; medications that can affect volume status or renal function (diuretics, angiotensin converting enzyme inhibitor [ACE-I] or angiotensin receptor blockers [ARBs]). Additional exclusion criteria were as follows: pregnancy, lactation, significant psychiatric illness, known allergy to PEG or $\mathrm{NaP}$, inability to provide informed consent.

\section{Randomization and Bowel Preparation Protocol}

All eligible patients were randomly assigned to ingest one of two preparation regimens using a randomization schedule generated by the website http://www.randomization. com by an investigator not involved in the colonoscopy procedure. The split-dose PEG group (Colyte, Taejoon Pharm. Inc., Seoul, Korea; 236 g PEG, 22.74 g Na$_{2} \mathrm{SO}_{4}$, $6.74 \mathrm{~g} \mathrm{NaHCO}_{3}, 5.86 \mathrm{~g} \mathrm{NaCl}$, and $2.97 \mathrm{~g} \mathrm{KCl}$ ) ingested 2 liters of PEG at $6 \mathrm{PM}$ on the day before the procedure and the remaining 2 liters in the early morning at least $2 \mathrm{~h}$ prior to the procedure. Patients were instructed to take PEG $250 \mathrm{~mL}$ every ten minutes. The NaP group (Solin Oral, Korea Pharm., Seoul, Korea; $48 \mathrm{~g} \mathrm{NaH}_{2} \mathrm{PO}_{4}, 18 \mathrm{~g}$ $\mathrm{Na}_{2} \mathrm{HPO}_{4}$ ) ingested $45 \mathrm{~mL}$ of $\mathrm{NaP}$ at $6 \mathrm{PM}$ on the day before the procedure and the remaining $45 \mathrm{~mL}$ of $\mathrm{NaP}$, separated temporally by a minimum of 10-12 h, at least 
$2 \mathrm{~h}$ prior to the colonoscopy on the day of the procedure. Patients taking NaP were instructed to drink at least $3 \mathrm{~L}$ of clear liquids.

Diet restrictions were identical for both preparation groups. All patients were told to start a low-fiber diet 3 days before the procedure and received instructions regarding an unacceptable foods list. On the day before colonoscopy, patients had a regular diet for breakfast and lunch, but a soft diet for dinner, and then they were allowed clear liquids until $2 \mathrm{~h}$ before the procedure on the day of the colonoscopy.

\section{Study Endpoints}

The primary end point of the study was to assess the quality of bowel preparation according to the Ottawa scale, including cleanliness and fluid quantity. The secondary end points included patient tolerability of bowel preparation using a patient questionnaire that consisted of compliance, acceptance, preference, and adverse events, including abdominal pain and bloating, nausea and vomiting, headache and dizziness, and sleep disturbance.

\section{Efficacy of Bowel Cleansing}

All study procedures were performed by three colonoscopists, two highly experienced staff members, and one fellow having experience with $>200$ colonoscopy cases, between 9 AM and 4 PM. The patient's endoscopist was not involved in the randomization process and remained blind to the preparation regimen through completion of the colonoscopy and scoring of the preparation quality. Bowel cleansing was evaluated using the Ottawa bowel preparation scale. This scale assesses cleanliness and fluid volume separately. Cleanliness was assessed for the right colon (cecum, ascending), mid colon (transverse, descending), and the rectosigmoid colon, individually, rated from 0 to 4 (no liquid $=0$; minimal liquid, no suctioning required $=$ 1 ; suction required to see mucosa $=2$; wash and suction $=3$; solid stool, not washable $=4$ ). Fluid quantity was rated from 0 to 2 for the entire colon (minimal $=0$; moderate $=1$; large $=3$ ). The Ottawa scale has a range from 0 (perfect) to 14 (solid stool in each colon segment and lots of fluid, i.e., a completely unprepared colon). Investigators participating in the study were instructed for assessment of bowel preparation quality according to this scale. Prior to starting the study, three colonoscopists performed calibration exercises involving 20 colonoscopies; interclass correlation coefficient (ICC) was then calculated for evaluation of reliability on the rating of bowel preparation quality. Once the colonoscopists were comfortable that they had a high level of agreement, the scales were then used in this study.

Tolerance of Bowel Preparation and Adverse Events

All patients arrived $30 \mathrm{~min}$ before their scheduled colonoscopy and met with an investigator who was not performing colonoscopy on the day of the procedure. Patients completed a questionnaire evaluating compliance, satisfaction, willingness to repeat the same regimen, and adverse events. Patient compliance with the two regimens was assessed by the amount of bowel preparation taken. Good compliance was defined as more than $75 \%$ taken. Acceptance of the preparation was rated on a three-point scale by asking about difficulty with ingestion of the two regimens $($ easy $=1$, tolerable $=2$, difficult $=3$ ). Preference was assessed by patient's choice for repeating the same regimen for a future colonoscopy. Patients were asked about the presence of any adverse events (abdominal pain and bloating, nausea and vomiting, headache and dizziness, sleep disturbance) during preparation and rated each symptom (none $=0$, mild $=1$, moderate $=2$, severe $=3$ ).

A blood test was performed 1 week prior to and on the day of colonoscopy. Changes in laboratory values were categorized relative to the baseline values. The estimated glomerular filtration rate (eGFR) was calculated using the modification of diet in renal disease (MDRD) formula [24] and the change of eGFR was assessed. We collected longterm follow-up data regarding renal function and electrolytes, especially in patients with significant laboratory abnormalities.

\section{Sample Size and Statistical Analysis}

The sample size calculation was based on comparison of a preparation quality score between the two groups. We hypothesized that preparation quality of split-dose PEG would be superior to that of NaP by more than $20 \%$. On the basis of data from previous studies, the estimated mean score for preparation quality using the Ottawa scale was 5. A sample size of 100 patients for each group was estimated to give $80 \%$ power at a two-sided alpha of 0.05 for detection of a 1.0 point difference in the Ottawa bowel preparation quality scale. We assumed a drop-out rate of $10 \%$ and planned to enroll a total of 220 patients. SAS software (SAS Institute, Cary, NC, USA) was used for performance of data analyses. Continuous variables were reported as mean \pm SD and categorical variables as percentages. Two-sided $t$-test was used to compare the means of continuous variables in the two groups, and Chi-square test was used to compare the categorical variables. A $P$ value $<0.05$ was considered statistically significant. 


\section{Results}

Baseline Characteristics

A total of 249 consecutive patients referred for outpatient colonoscopy were assessed for eligibility (Fig. 1). Thirty one patients were excluded and 218 patients were randomly assigned to receive one of the two regimens. Ten patients cancelled the procedure and 208 patients were allocated to bowel preparation for colonoscopy. The success rate of colonoscopy was $99.5 \%$. Only one procedure was not completed because of severe pain. Data from failed procedures were excluded from the final analyses, and 207 patients were finally included for analyses, of whom 103 received splitdose PEG and 104 received $\mathrm{NaP}$. A combination of pethidine hydrochloride $(25 \mathrm{mg})$ and midazolam $(2.5 \mathrm{mg})$ as an intravenous bolus was used for sedation in patients for whom there was no contraindication. Total dose of midazolam or pethidine used for sedation was not different in the two groups. There was no significant difference between the two groups for the mean time to cecal intubation (split-dose PEG: $8.0 \pm 4.7 \mathrm{~min}$ vs. $\mathrm{NaP}: \quad 8.50 \pm 5.9 \mathrm{~min} ; \quad P=0.175)$. Table 1 summarizes the characteristics of the patients and indications for colonoscopy. The most common reasons for colonoscopy were screening and surveillance without any symptoms and the most common symptoms for indication were abdominal pain, discomfort, and bloating. No significant differences were observed between the two groups with respect to baseline characteristics.

\section{Efficacy of Bowel Cleansing}

Distributions of the four Ottawa scale items are shown in Table 2. There was no significant difference between the two groups for the mean total score (split-dose PEG: $5.85 \pm 1.85$ vs. NaP: $5.50 \pm 1.94 ; P=0.181$ ). Significantly greater residual colonic fluid was seen in the splitdose PEG group than in the NaP group, and mean fluid score was $1.24 \pm 0.49$ vs. $1.04 \pm 0.53$, respectively $(P=0.007)$. The bowel preparation score was separately assessed for the

Fig. 1 Flow diagram of patients. Single asterisk indicates angiotensin converting enzyme inhibitor; double asterisk indicates angiotensin receptor blockers

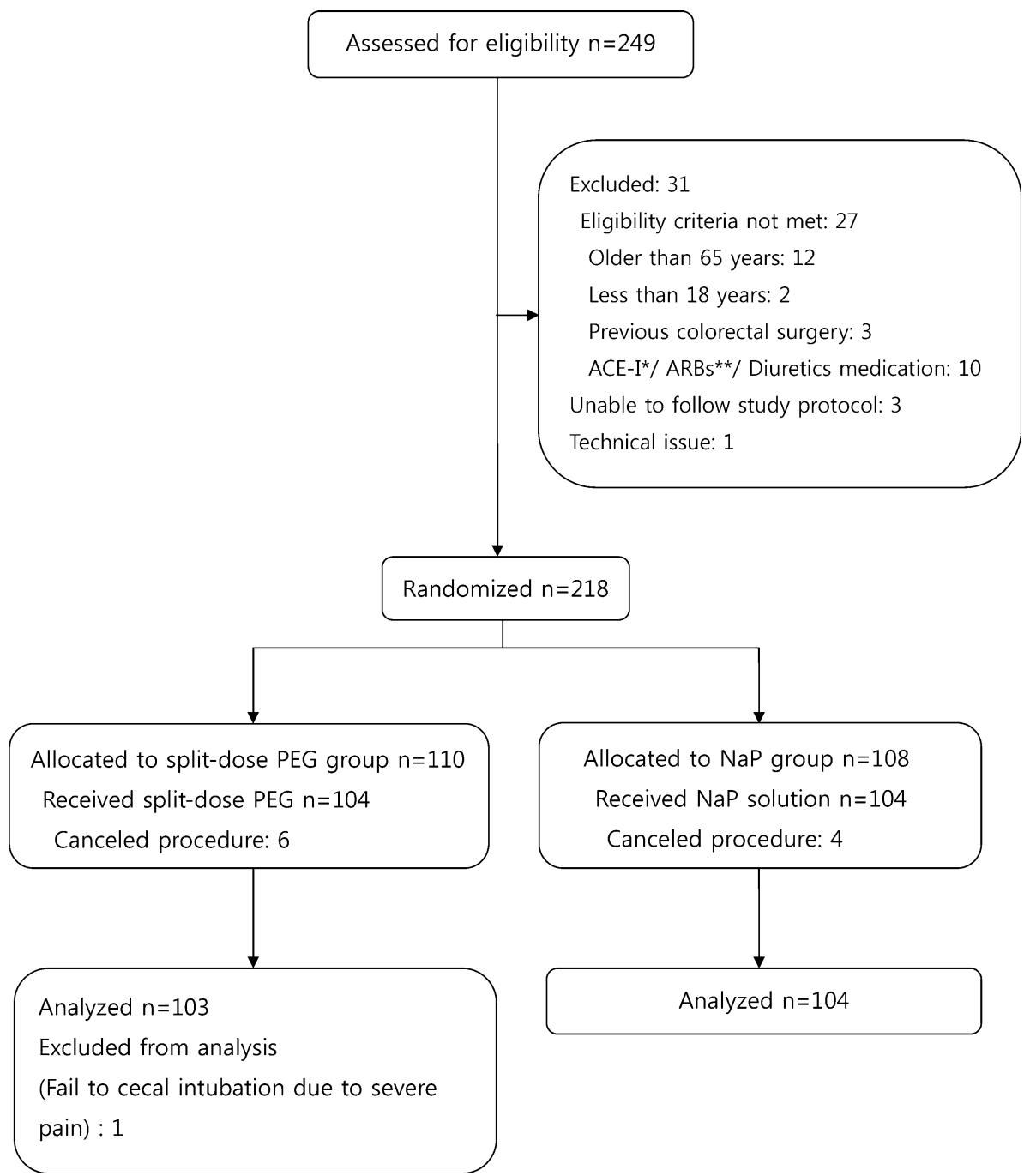


Table 1 Baseline characteristics
Values are means \pm standard deviation (SD) or $N(\%)$

$P E G$ polyethylene glycols, IBS irritable bowel syndrome

\begin{tabular}{|c|c|c|c|}
\hline Characteristics & $\begin{array}{l}\text { Split-dose PEG } \\
(N=103)\end{array}$ & $\begin{array}{l}\text { Sodium phosphate } \\
(N=104)\end{array}$ & $P$ value \\
\hline Age (years) & $49.3 \pm 10.5$ & $49.0 \pm 9.4$ & 0.812 \\
\hline Male:female & $48(46.6) / 55(53.4)$ & $56(53.8) / 48(46.2)$ & 0.297 \\
\hline Body mass index $\left(\mathrm{kg} / \mathrm{m}^{2}\right)$ & $23.5 \pm 2.9$ & $22.9 \pm 2.4$ & 0.140 \\
\hline Experience of colonoscopy & $35(34.0)$ & $35(33.7)$ & 0.960 \\
\hline Previous surgical history & $20(19.4)$ & $22(21.2)$ & 0.756 \\
\hline Abdominal operation & $12(11.7)$ & $12(11.5)$ & \\
\hline Pelvic or gynecologic operation & $8(7.8)$ & $10(9.6)$ & \\
\hline Family history of colon cancer & $4(3.9)$ & $4(3.8)$ & 0.989 \\
\hline Past medical history & & & 0.383 \\
\hline Hypertension & $10(9.7)$ & $8(7.7)$ & \\
\hline Diabetes & $6(5.8)$ & $1(1.0)$ & \\
\hline Cardiovascular disease & $1(1.0)$ & $2(1.9)$ & \\
\hline Thyroid disease & $4(3.9)$ & $4(3.8)$ & \\
\hline Others & $4(3.9)$ & $2(1.9)$ & \\
\hline \multicolumn{4}{|l|}{ Indication } \\
\hline Screening & $60(58.3)$ & $62(59.6)$ & 0.482 \\
\hline Surveillance & $11(10.6)$ & $8(7.7)$ & 0.457 \\
\hline Symptoms & $32(31.1)$ & $34(32.7)$ & 0.802 \\
\hline Red flag sign & $6(5.9)$ & $10(9.7)$ & 0.307 \\
\hline Rectal bleeding & $5(4.9)$ & $9(8.7)$ & \\
\hline Positive stool occult blood & $0(0)$ & $1(1.0)$ & \\
\hline Significant weight loss & $1(1.0)$ & $0(0)$ & \\
\hline IBS symptoms & $26(25.2)$ & $24(23.0)$ & 0.903 \\
\hline Abdominal pain/discomfort/bloating & $16(15.5)$ & $14(13.4)$ & \\
\hline Change of bowel habit & $2(1.9)$ & $6(5.8)$ & \\
\hline Constipation & $3(2.9)$ & $3(2.9)$ & \\
\hline Diarrhea & $5(4.9)$ & $1(0.9)$ & \\
\hline
\end{tabular}

Table 2 The efficacy of bowel cleansing according to Ottawa scale

\begin{tabular}{llll}
\hline $\begin{array}{l}\text { Location / } \\
\text { measurement }\end{array}$ & $\begin{array}{l}\text { Split-dose PEG } \\
(N=103)\end{array}$ & $\begin{array}{l}\text { Sodium phosphate } \\
(N=104)\end{array}$ & $P$ value \\
\hline Right colon & $1.91 \pm 0.71$ & $2.03 \pm 0.76$ & 0.222 \\
Mid colon & $1.65 \pm 0.62$ & $1.49 \pm 0.75$ & 0.096 \\
Rectosigmoid colon & $1.01 \pm 0.65$ & $0.97 \pm 0.67$ & 0.676 \\
Fluid volume & $1.24 \pm 0.49$ & $1.04 \pm 0.53$ & $0.007^{*}$ \\
Total score & $5.85 \pm 1.85$ & $5.50 \pm 1.94$ & 0.181 \\
\hline
\end{tabular}

Data are means \pm standard deviation (SD)

$P E G$ polyethylene glycols

$* P<0.05$ was considered statistically significant

right, middle, and rectosigmoid colon according to the Ottawa scale. The right colon was consistently more difficult to clean, with no significant group differences (splitdose PEG: $1.91 \pm 0.71$ vs. NaP: $2.03 \pm 0.76 ; P=0.222$ ). There was no significant difference in bowel preparation for the middle colon (split-dose PEG: $1.65 \pm 0.62$ vs. NaP:
$1.49 \pm 0.75 ; P=0.096$ ) or the rectosigmoid colon (splitdose PEG: $1.01 \pm 0.65$ vs. NaP: $0.97 \pm 0.67 ; P=0.676$ ).

\section{Patient Tolerance and Adverse Events}

Patient compliance, preference, acceptance and adverse events are shown in Table 3. Patient compliance with a two preparation regimen was high with no significant differences (split-dose PEG: $95.1 \%$ vs. NaP: $99 \% ; P=0.095$ ). To assess the preference of the assigned preparation regimen, patients were asked whether they would be willing to repeat the same preparation regimen if needed. Patients who would choose the same regimen in the future were similar in the two groups (split-dose PEG: $63.1 \%$ vs. NaP: $70.2 \% ; P=0.280$ ). Bowel preparations were generally not well tolerated by patients. Patients' acceptance was evaluated by asking about difficulty in taking the regimen. Seventy one of 207 patients (34.3\%) answered difficult, 75 of 207 patients (36.3\%) replied tolerant, and only 61 of 207 
Table 3 Patient compliance, preference and acceptance and adverse events
Data are means \pm standard deviation (SD)

$P E G$ polyethylene glycols

$* P<0.05$ was considered statistically significant

\begin{tabular}{|c|c|c|c|}
\hline Parameter & $\begin{array}{l}\text { Split-dose PEG } \\
(N=103)\end{array}$ & $\begin{array}{l}\text { Sodium phosphate } \\
(N=104)\end{array}$ & $P$ value \\
\hline Compliance $(>75 \%$ taken dose) & $98(95.1)$ & $103(99)$ & 0.095 \\
\hline Preference & $65(63.1)$ & $73(70.2)$ & 0.280 \\
\hline Acceptance & & & 0.408 \\
\hline 1 (easy) & $26(25.2)$ & $35(33.7)$ & \\
\hline 2 (tolerant) & 39 (37.9) & $36(34.6)$ & \\
\hline 3 (difficult) & $38(36.9)$ & $33(31.7)$ & \\
\hline Adverse events & $52(50.5)$ & $66(63.5)$ & 0.059 \\
\hline Abdominal pain/discomfort & & & 0.077 \\
\hline 0 (none) & $61(58.2)$ & $56(58.8)$ & \\
\hline 1 (mild) & $23(22.3)$ & $33(31.7)$ & \\
\hline 2 (moderate) & $10(9.7)$ & $13(11.6)$ & \\
\hline 3 (severe) & $9(8.7)$ & $2(1.9)$ & \\
\hline Nausea/vomiting & & & $0.036^{*}$ \\
\hline 0 (none) & $71(68.9)$ & $57(54.8)$ & \\
\hline 1 (mild) & $19(18.4)$ & $23(22.1)$ & \\
\hline 2 (moderate) & $7(6.8)$ & $20(19.2)$ & \\
\hline 3 (severe) & $6(5.8)$ & $4(3.8)$ & \\
\hline Headache/dizziness & & & 0.085 \\
\hline 0 (none) & $82(79.6)$ & $70(67.3)$ & \\
\hline 1 (mild) & $13(12.6)$ & $26(25.0)$ & \\
\hline 2 (moderate) & $5(4.9)$ & $7(6.7)$ & \\
\hline 3 (severe) & $3(2.9)$ & $1(1.0)$ & \\
\hline Sleep disturbance & & & 0.930 \\
\hline 0 (none) & $87(84.5)$ & $85(81.7)$ & \\
\hline 1 (mild) & $9(8.7)$ & $12(11.5)$ & \\
\hline 2 (moderate) & $6(5.8)$ & $6(5.8)$ & \\
\hline 3 (severe) & $1(1.0)$ & $1(1.0)$ & \\
\hline
\end{tabular}

patients $(29.5 \%)$ answered that taking the bowel preparation regimen was easy. There was no significant difference between the two groups $(P=0.408)$. One hundred eighteen of 207 patients (57\%) experienced adverse events, including abdominal pain/discomfort, nausea/vomiting, headache/dizziness, and sleep disturbance. Patients in the $\mathrm{NaP}$ group experienced more adverse events compared with the split-dose PEG group, although the difference was not statistically significant (split-dose PEG: 52/103 [50.5\%] vs. NaP: 66/104 [63.5\%]; $P=0.059$ ). Patients in the split-dose PEG group had significantly fewer complaints regarding nausea/vomiting compared with the $\mathrm{NaP}$ group $(P=0.036)$. There was no significant difference in abdominal pain/discomfort, headache/dizziness, and sleep disturbance between the two groups $(P=0.077,0.085$ and 0.930 , respectively). There were no serious adverse events or preparation-related complications that required specific treatment or hospitalization among the study patients.

\section{Laboratory Changes}

Table 4 presents baseline laboratory tests and those changes for both preparation groups. Transient fluctuations of specified serum electrolytes were greater in magnitude in the NaP group. However, none of the enrolled patients presented overt clinical manifestations related to these changes. No significant changes occurred in the blood urea nitrogen (BUN), creatinine and eGFR in the two groups. In the NaP group, there were statistically significant decreases in serum potassium, calcium from baseline, but these data were almost within normal limits. The split-dose PEG group was associated with minimal changes in these electrolytes and those changes were less than the NaP group. Serum inorganic phosphorus was significantly increased to abnormal levels in most patients in the NaP group after preparation. However, these values had returned to normal levels at the follow-up blood test 1 week after colonoscopy $(3.07 \pm 0.35 \mathrm{mg} / \mathrm{dL})$. 
Table 4 Laboratory data

\begin{tabular}{|c|c|c|c|c|c|c|c|}
\hline \multirow[t]{2}{*}{ Measurement } & \multicolumn{3}{|c|}{ Split-dose PEG } & \multicolumn{3}{|c|}{ Sodium phosphate } & \multirow[t]{2}{*}{$P$ value } \\
\hline & Baseline & Post-prep & Mean difference & Baseline & Post-prep & Mean difference & \\
\hline $\mathrm{Cr}(\mathrm{mg} / \mathrm{dL})$ & 0.91 & 0.95 & $0.04 \pm 0.04$ & 0.90 & 0.97 & $0.06 \pm 0.05$ & 0.08 \\
\hline BUN (mg/dL) & 13.64 & 12.96 & $-0.67 \pm 0.83$ & 12.01 & 11.43 & $-0.58 \pm 0.87$ & 0.60 \\
\hline $\mathrm{Na}(\mathrm{mEq} / \mathrm{L})$ & 140.52 & 141.08 & $0.48 \pm 0.93$ & 139.53 & 140.90 & $1.32 \pm 1.28$ & $0.002 *$ \\
\hline $\mathrm{K}(\mathrm{mEq} / \mathrm{L})$ & 4.16 & 4.05 & $-0.14 \pm 0.15$ & 4.01 & 3.72 & $-0.32 \pm 0.16$ & $<0.001 *$ \\
\hline Calcium (mEq/L) & 8.94 & 8.88 & $-0.05 \pm 0.14$ & 8.99 & 8.70 & $-0.29 \pm 0.22$ & $<0.001 *$ \\
\hline IP (mg/dL) & 3.43 & 3.54 & $0.11 \pm 0.73$ & 3.04 & 6.50 & $3.46 \pm 1.51$ & $<0.001 *$ \\
\hline $\mathrm{eGFR}\left(\mathrm{mL} / \mathrm{min} / 1.73 \mathrm{~m}^{2}\right)$ & 85.23 & 80.16 & $-5.62 \pm 5.24$ & 86.15 & 80.31 & $-6.13 \pm 6.00$ & 0.06 \\
\hline
\end{tabular}

Data are means \pm standard deviation (SD)

$P E G$ polyethylene glycols

$* P<0.05$ was considered statistically significant

\section{Discussion}

In this study, we demonstrated that split-dose PEG was equally effective and better tolerated than split-dose $\mathrm{NaP}$ for bowel preparation. Conventional one-dose PEG and $\mathrm{NaP}$ had equal bowel cleansing efficacy and split-dose PEG was superior to the conventional one-dose regimen; therefore, we initially hypothesized that bowel cleansing with split-dose PEG would be better than that with splitdose NaP. Being inconsistent with our initial hypothesis, bowel cleansing quality was similar between split-dose PEG and split-dose NaP. In general, conventional one-dose PEG is less tolerable than split-dose NaP. In this study, split-dose PEG was more tolerable than split-dose NaP in terms of having fewer adverse events, such as nausea and vomiting, which was consistent with our initial hypothesis. And $\mathrm{NaP}$ preparation was associated with hypokalemia, hypocalemia and hyperphosphatemia compared with splitdose PEG. However, levels of potassium and calcium were almost within normal limits and the level of phosphates returned to normal range 1 week after colonoscopy. We did not observe any clinical manifestations related to these electrolyte abnormalities, and no patients needed any specific treatments. Our study was not powered to detect clinical adverse events, particularly in the healthy population that we studied.

Only one prior study has evaluated efficacy, tolerability, and safety comparing split-dose PEG and NaP. Ell et al. found that split-dose PEG was more effective in bowel preparation than $\mathrm{NaP}$ as well as being more tolerable and having a lower incidence of adverse events than $\mathrm{NaP}$ [25]. However, the study enrolled a relatively small number of patients and mainly inpatients, and split-dose was variable between patients taking 2-3 L and 1-2 L of PEG. This study enrolled a large number of patients and all patients were outpatients. Also, we used a fixed split dosing of PEG in the evening $(2 \mathrm{~L}) /$ morning $(2 \mathrm{~L})$. Another point that differed from previous studies was diet restriction before the day of the procedure. We chose a minimum diet restriction consisting of a regular breakfast and lunch, and a soft diet only for dinner on the day prior to colonoscopy, followed by a clear liquid diet up to $2 \mathrm{~h}$ before the procedure. Though many physicians order patients to take only a clear liquid diet for $24 \mathrm{~h}$ prior to colonoscopy, several studies support a less restrictive diet [26-28]. Siddiqui et al. found that there was no significant relationship between bowel-preparation quality and the interval from the time of the last solid meal to the start of colonoscopy [29]. This suggests that strict diet restriction, such as a clear liquid diet on the day before the colonoscopy is not always necessary. There is no generally accepted standard for preprocedure fasting guidelines for split-dose regimens. Guidelines from the American Society of Anesthesiology support a minimum fasting period of $2 \mathrm{~h}$ for clear liquids and $6 \mathrm{~h}$ for light meals before sedation [30]. Diet protocol of our study did not interfere with the above fasting guidelines and it could be very feasible for outpatients with respect to less interference in daily life and work, leading to improved quality of life.

We used the Ottawa scoring system for bowel cleansing, which is a simple, objectively framed bowel preparation quality scale. It assesses colonic segments individually and colonic fluid overall, and provides a summary score for the entire colon. The scoring system of the previous study comparing split-dose PEG with $\mathrm{NaP}$ did not consider fluid quantity. In the present study, split-dose PEG and NaP had similar cleansing efficacy in terms of the total cleansing score. However, PEG has a greater quantity of fluid remaining in the colon than $\mathrm{NaP}$ and the remaining fluid does not usually decrease colonoscopic visualization as 
much as fecal materials in the colon. In light of this, colonoscopic visualization of PEG might be superior to that of $\mathrm{NaP}$.

This study has several potential limitations. First, this randomized controlled trial was conducted at a single center and enrolled outpatients without significant medical problems and excluded those who experienced colorectal surgery. Considering that colonoscopy is performed mostly in outpatients in our country, we conducted the study in an outpatient setting. Considering NaP-related complications, such as acute phosphate nephropathy or serious electrolyte imbalance, the exclusions were necessary. The results of our study require further confirmation through multicenter randomized trials including an unselected group of patients. Second, we did not control the timing of colonoscopy in the two groups, which is one of the potential factors influencing bowel cleansing. Several previous studies have demonstrated that the interval between the last dose of bowel preparation regimen and the start of colonoscopy affects the quality of the bowel preparation [29, 31-33]. However, these studies employed a one-dose preparation regimen or combined different regimens. Recommended optimal interval between the time of preparation and the start of colonoscopy had a wide range of 4-14 h [29, 31, 32]. In the present study, colonoscopies were performed both in the morning and afternoon and within $2-10 \mathrm{~h}$ after the second dose of the preparation regimen. However, there was no significant difference in the time interval from preparation to procedure between both groups. Third, we did not evaluate technical parameters, such as technical difficulty, and adenoma detection rate, which could be related to bowel cleansing quality. This was because the three colonoscopists participating in this study had different levels of skill, which could cause significant bias in evaluation of technical parameters.

Although a split dosing regimen improved patient's tolerability to bowel preparation, acceptance rate was low (29.5\%). This means that bowel preparation with a split dosing regimen is still unpleasant to patients. Patients should wake early in the morning to take a second dose of bowel preparation and might experience more frequent bathroom stops or episodes of fecal soiling while traveling to the endoscopy center. As previous studies have indicated, explanations from medical staff members to patients regarding the importance of adequate bowel preparation for colonoscopy, adverse events, and rationale of split dosing could improve patients' tolerability [33-35]. These are important for enhancement of tolerability in addition to development of a new preparation regimen.

In conclusion, this randomized trial demonstrated that split-dose PEG produced equal preparation quality compared with split-dose NaP. Considering that PEG generally has a greater quantity of fluid remaining in the colon than
$\mathrm{NaP}$ and that remaining fluid usually does not decrease colonoscopic visualization as much as fecal materials, PEG might have superior bowel cleansing quality over $\mathrm{NaP}$. Patients' tolerability was better in the split-dose PEG group in terms of having fewer adverse events such as nausea and vomiting than NaP. And split-dose PEG had a better safety profile related to serum electrolytes. We found that a minimal diet restriction was convenient and feasible for routine colonoscopy. We recommend that split-dose PEG bowel preparation is superior to a split-dose NaP preparation with regard to patient tolerance and patient safety and for good visualization of the colon. And the above results of this study should apply to outpatient scheduled colonoscopies.

Open Access This article is distributed under the terms of the Creative Commons Attribution Noncommercial License which permits any noncommercial use, distribution, and reproduction in any medium, provided the original author(s) and source are credited.

\section{References}

1. Harewood GC, Sharma VK, de Garmo P. Impact of colonoscopy preparation quality on detection of suspected colonic neoplasia. Gastrointest Endosc. 2003;58:76-79.

2. Froehlich F, Wietlisbach V, Gonvers JJ, Burnand B, Vader JP. Impact of colonic cleansing on quality and diagnostic yield of colonoscopy: the European Panel of Appropriateness of Gastrointestinal Endoscopy European multicenter study. Gastrointest Endosc. 2005;61:378-384.

3. Wexner SD, Beck DE, Baron TH, et al. A consensus document on bowel preparation before colonoscopy: prepared by a task force from the American Society of Colon and Rectal Surgeons (ASCRS), the American Society for Gastrointestinal Endoscopy (ASGE), and the Society of American Gastrointestinal and Endoscopic Surgeons (SAGES). Gastrointest Endosc. 2006;63: 894-909.

4. El Sayed AM, Kanafani ZA, Mourad FH, et al. A randomized single-blind trial of whole versus split-dose polyethylene glycolelectrolyte solution for colonoscopy preparation. Gastrointest Endosc. 2003;58:36-40.

5. Park JS, Sohn CI, Hwang SJ, et al. Quality and effect of single dose versus split-dose of polyethylene glycol bowel preparation for early-morning colonoscopy. Endoscopy. 2007;39:616-619.

6. Abdul-Baki H, Hashash JG, Elhajj II, et al. A randomized, controlled, double-blind trial of the adjunct use of tegaserod in whole-dose or split-dose polyethylene glycol electrolyte solution for colonoscopy preparation. Gastrointest Endosc. 2008;68:294300 (quiz 334, 336).

7. Di Palma JA, Rodriguez R, McGowan J, Cleveland MB. A randomized clinical study evaluating the safety and efficacy of a new, reduced-volume, oral sulfate colon-cleansing preparation for colonoscopy. Am J Gastroenterol. 2009;104:2275-2284.

8. Tan JJ, Tjandra JJ. Which is the optimal bowel preparation for colonoscopy - a meta-analysis. Colorectal Dis. 2006;8:247-258.

9. Vanner SJ, MacDonald PH, Paterson WG, et al. A randomized prospective trial comparing oral sodium phosphate with standard polyethylene glycol-based lavage solution (Golytely) in the preparation of patients for colonoscopy. Am J Gastroenterol. 1990;85:422-427. 
10. Poon CM, Lee DW, Mak SK, et al. Two liters of polyethylene glycol-electrolyte lavage solution versus sodium phosphate as bowel cleansing regimen for colonoscopy: a prospective randomized controlled trial. Endoscopy. 2002;34:560-563.

11. Cohen SM, Wexner SD, Binderow SR, et al. Prospective, randomized, endoscopic-blinded trial comparing precolonoscopy bowel cleansing methods. Dis Colon Rectum. 1994;37:689-696.

12. Henderson JM, Barnett JL, Turgeon DK, et al. Single-day, divided-dose oral sodium phosphate laxative versus intestinal lavage as preparation for colonoscopy: efficacy and patient tolerance. Gastrointest Endosc. 1995;42:238-243.

13. Young CJ, Simpson RR, King DW, Lubowski DZ. Oral sodium phosphate solution is a superior colonoscopy preparation to polyethylene glycol with bisacodyl. Dis Colon Rectum. 2000;43: 1568-1571.

14. Hookey LC, Depew WT, Vanner S. The safety profile of oral sodium phosphate for colonic cleansing before colonoscopy in adults. Gastrointest Endosc. 2002;56:895-902.

15. Aasebo W, Scott H, Ganss R. Kidney biopsies taken before and after oral sodium phosphate bowel cleansing. Nephrol Dial Transplant. 2007;22:920-922.

16. Beyea A, Block C, Schned A. Acute phosphate nephropathy following oral sodium phosphate solution to cleanse the bowel for colonoscopy. Am J Kidney Dis. 2007;50:151-154.

17. Desmeules S, Bergeron MJ, Isenring P. Acute phosphate nephropathy and renal failure. $N$ Engl J Med. 2003;349:10061007.

18. Gonlusen G, Akgun H, Ertan A, Olivero J, Truong LD. Renal failure and nephrocalcinosis associated with oral sodium phosphate bowel cleansing: clinical patterns and renal biopsy findings. Arch Pathol Lab Med. 2006;130:101-106.

19. Markowitz GS, Nasr SH, Klein P, et al. Renal failure due to acute nephrocalcinosis following oral sodium phosphate bowel cleansing. Hum Pathol. 2004;35:675-684.

20. Seol DC, Hong SN, Kim JH, et al. Change in renal function after sodium phosphate preparation for screening colonoscopy. World J Gastroenterol. 2010;16:2010-2016.

21. Rex DK, Vanner SJ. Colon cleansing before colonoscopy: does oral sodium phosphate solution still make sense? Can J Gastroenterol. 2009;23:210-214.

22. Ozturk NA, Gokturk HS, Demir M, et al. Efficacy and safety of sodium phosphate for colon cleansing in type 2 diabetes mellitus. South Med J. 2010;103:1097-1102.

23. Korsten MA, Spungen AM, Rosman AR, et al. A prospective assessment of renal impairment after preparation for colonoscopy: oral sodium phosphate appears to be safe in well-hydrated subjects with normal renal status. Dig Dis Sci. 2010;55:20212029.

24. Levey AS, Bosch JP, Lewis JB, et al. A more accurate method to estimate glomerular filtration rate from serum creatinine: a new prediction equation. Modification of diet in renal disease study group. Ann Intern Med. 1999;130:461-470.

25. Ell C, Fischbach W, Keller R, et al. A randomized, blinded, prospective trial to compare the safety and efficacy of three bowel-cleansing solutions for colonoscopy (HSG-01*). Endoscopy. 2003;35:300-304.

26. Aoun E, Abdul-Baki H, Azar C, et al. A randomized single-blind trial of split-dose PEG-electrolyte solution without dietary restriction compared with whole dose PEG-electrolyte solution with dietary restriction for colonoscopy preparation. Gastrointest Endosc. 2005;62:213-218.

27. Reilly T, Walker G. Reasons for poor colonic preparation with inpatients. Gastroenterol Nurs. 2004;27:115-117.

28. Adams WJ, Meagher AP, Lubowski DZ, King DW. Bisacodyl reduces the volume of polyethylene glycol solution required for bowel preparation. Dis Colon Rectum. 1994;37:229-233 (discussion 233-224).

29. Siddiqui AA, Yang K, Spechler SJ, et al. Duration of the interval between the completion of bowel preparation and the start of colonoscopy predicts bowel-preparation quality. Gastrointest Endosc. 2009;69:700-706.

30. American Society of Anesthesiologist Task Force on Preoperative Fasting. Practice guidelines for preoperative fasting and the use of pharmacologic agents to reduce the risk of pulmonary aspiration: application to healthy patients undergoing elective procedures: a report by the American Society of Anesthesiologist Task Force on Preoperative Fasting. Anesthesiology 1999;90: 896-905.

31. Marmo R, Rotondano G, Riccio G, et al. Effective bowel cleansing before colonoscopy: a randomized study of split-dosage versus non-split dosage regimens of high-volume versus lowvolume polyethylene glycol solutions. Gastrointest Endosc. 2010;72:313-320.

32. Eun CS, Han DS, Hyun YS, et al. The timing of bowel preparation is more important than the timing of colonoscopy in determining the quality of bowel cleansing. Dig Dis Sci. 2011;56:539-544.

33. Parra-Blanco A, Nicolas-Perez D, Gimeno-Garcia A, et al. The timing of bowel preparation before colonoscopy determines the quality of cleansing, and is a significant factor contributing to the detection of flat lesions: a randomized study. World J Gastroenterol. 2006;12:6161-6166.

34. Unger RZ, Amstutz SP, Seo da H, Huffman M, Rex DK. Willingness to undergo split-dose bowel preparation for colonoscopy and compliance with split-dose instructions. Dig Dis Sci. 2010;55:2030-2034.

35. Cohen LB, Kastenberg DM, Mount DB, Safdi AV. Current issues in optimal bowel preparation: experts from a roundtable discussion among colon-cleansing experts. Eur J Gastroenterol Hepatol. 2009;5:1-11. 